\title{
Salience, Credibility, Legitimacy and Boundaries: Linking Research, Assessment and Decision Making
}

\section{Citation}

David Cash, William C. Clark, Frank Alcock, Nancy M. Dickson, Noelle Eckley, Jill Jäger. Salience, Credibility, Legitimacy and Boundaries: Linking Research, Assessment and Decision Making. KSG Working Papers Series, 2003.

\section{Published Version}

10.2139/ssrn.372280

\section{Permanent link}

http://nrs.harvard.edu/urn-3:HUL.InstRepos:32067415

\section{Terms of Use}

This article was downloaded from Harvard University's DASH repository, and is made available under the terms and conditions applicable to Other Posted Material, as set forth at http:// nrs.harvard.edu/urn-3:HUL.InstRepos:dash.current.terms-of-use\#LAA

\section{Share Your Story}

The Harvard community has made this article openly available.

Please share how this access benefits you. Submit a story.

\section{Accessibility}




\section{John F. Kennedy School of Government Harvard University Faculty Research Working Papers Series}

\section{Salience, Credibility, Legitimacy and Boundaries: Linking Research, Assessment and Decision Making \\ David Cash, William Clark, Frank Alcock, Nancy Dickson, Noelle Eckley, and Jill Jäger}

November 2002

RWP02-046

The views expressed in the KSG Faculty Research Working Paper Series are those of the author(s) and do not necessarily reflect those of the John F. Kennedy School of Government or Harvard University. All works posted here are owned and copyrighted by the author(s). Papers may be downloaded for personal use only. 


\title{
Salience, Credibility, Legitimacy and Boundaries: Linking Research, Assessment and Decision Making
}

\author{
David Cash, William Clark, Frank Alcock, Nancy Dickson, Noelle Eckley and Jill Jäger
}

\begin{abstract}
The boundary between science and policy is only one of several boundaries that hinder the linking of scientific and technical information to decision making. Managing boundaries between disciplines, across scales of geography and jurisdiction, and between different forms of knowledge is also often critical to transferring information. The research presented in this paper finds that information requires three (not mutually exclusive) attributes - salience, credibility, and legitimacy - and that what makes boundary crossing difficult is that actors on different sides of a boundary perceive and value salience, credibility, and legitimacy differently. Presenting research on water management regimes in the United States, international agricultural research systems, El Niño forecasting systems in the Pacific and southern Africa, and fisheries in the North Atlantic, this paper explores: 1) how effective boundary work involves creating salient, credible, and legitimate information simultaneously for multiple audiences; 2) the thresholds, complementarities and tradeoffs between salience, credibility, and legitimacy when crossing boundaries; and 3) propositions for institutional mechanisms in boundary organizations which effectively balance tradeoffs, take advantage on complementarities, and reach thresholds of salience, credibility, and legitimacy.
\end{abstract}

\section{INTRODUCTION}

Effectively linking knowledge and action to meet the needs of human development while protecting fundamental biophysical systems has proven to be a chronically difficult task. This difficulty in linking knowledge and action, even when there is political commitment to sustainable development, has been attributed to, among other factors, barriers or gaps in knowledge-action systems. Such impediments result in the archetypal problems of decision makers not getting information that they need and scientists producing information that is not used.

The challenges associated with barriers or gaps has led to a growing body of work that analyzes "boundaries" in knowledge-action systems (Jasanoff 1987; Jasanoff 1990; Gieryn 1995; Guston 2001). Such boundaries demarcate the socially constructed and negotiated borders between science and policy, between disciplines, across nations, and across multiple levels. They serve important functions (e.g., protecting science from the biasing influence of politics, or helping organize and allocate authority), but they can also act as barriers to communication, collaboration, and integrated assessment and action. Managing such boundaries seems to be a fundamental element in effectively linking knowledge to action.

As important as managing boundaries is, it is only one piece of the puzzle of effectively linking knowledge and action - a piece that is interconnected with the challenges of creating

\footnotetext{
${ }^{1}$ This paper is based on research supported (in part) by a grant from the National Science Foundation (award BCS0004236) with contributions from the National Oceanic and Atmospheric Administration's Office of Global Programs for the Research and Assessment Systems for Sustainability Program.
} 
salient, credible, and legitimate information. Traditionally, scientists, managers and scholars of science, technology and policy have focused on credibility - how to create authoritative, believable, and trusted information (Price 1965; Wildavsky 1987). For example, during the creation of such bodies as the Intergovernmental Panel on Climate Change (IPCC), priority was given to creating organizational structures that assure credibility of the information being produced - through peer review, rigorous vetting of participants, etc. (Agrawala 1998). Recent research and practice, however, point to the danger of overestimating the importance of credibility alone, while undervaluing two other attributes of science and technology systems: salience (how relevant information is to decision making bodies or publics) and legitimacy (how "fair" an information producing process is and whether it considers appropriate values, concerns, and perspectives of different actors.) Paying too little attention to salience is exemplified in the case of the Global Biodiversity Assessment, in which the primary intended audience (parties to the Convention on Biological diversity) had little interest in the kinds of questions that were being asked by the assessors. Information relevant to their decision making was not produced and the assessment was largely ignored by the intended audience (Raustiala and Victor 1996). Likewise, too little focus on legitimacy is seen in the early stages of the IPCC, in which developing country participants began to question the lack of third world scientists and perspectives in the assessment process (Agrawala 1998).

Given the challenge of creating salient, credible, and legitimate information in a world of boundaries, the central institutional question that drives the research presented in this paper is:

What are the kinds of organizational structures and strategies that effectively help manage boundaries to link salient, credible and legitimate science and technology to decision making for sustainable development?

By way of answering this question, in this paper we will: present an emerging framework for thinking about boundaries and salience, credibility, and legitimacy (Section 2); describe our empirical findings (Section 3); and present conclusions and implications for organizations engaged in producing and using knowledge for sustainable development (Section 4). Section 5 offers concluding remarks.

\section{A Framework For Thinking About Linking KNOWLEDge AND ACtion: SALIENCE, CREDIBILITY, AND LEgITIMACY AND BOUNDARIES}

\subsection{Caricatures of linking knowledge to action}

What are the dynamics of salience, credibility, and legitimacy in a world of boundaries? A simple set of caricatures of connecting knowledge to action across boundaries helps to illuminate the compounding interactions.

Consider a situation where a single scientist provides knowledge for a single decision maker. They are separated by institutional boundaries. Each works in a setting with characteristic rules, norms and procedures. What the scientist considers relevant information may not be the same as what the decision maker considers relevant, and vice versa. There must be some way that the expert can know what kinds of questions to ask in order to produce knowledge that is salient to the decision maker. For this to occur, the "boundary" needs to be bridged - that is, the scientist must communicate somehow with the decision 
maker. Without this bridging, there is little chance that the information will be salient, and thus found to be useful by the decision maker.

Next, we can complicate the situation by adding a second scientist (perhaps from a different region of the world or a different scientific discipline). The two scientists provide different information and conflicting recommendations. In this case, the decision maker will likely listen to the source and/or information that she views as more plausible and/or accurate. Who, then, is the decision maker to believe and why? What are the criteria by which a decision maker will judge the believability or trustworthiness of the two scientists? Holding salience constant, the expert who is most credible will be most likely to influence decision making. Information that is not credible, regardless of how salient, is likely to be ignored.

Inversely, we can complicate the situation by adding multiple decision makers. This situation helps us to illuminate the issue of legitimacy. Here, how problems are framed, how concerns are addressed and how policy options are considered all affect how the various decision makers view the system of connecting knowledge to action as more or less "fair." What is a fair process by which decision making happens, and what is a fair and legitimate process through which experts are engaged in the scientific endeavor? How are research agendas set, concerns placed on the table, and dimensions of the problem chosen and focused upon? How are boundaries bridged between the two decision makers, between the expert and decision makers, and between all three actors in such a way that legitimacy is facilitated? As in the previous world, it is possible that regardless of how salient or credible information is, if the process of producing and using information is not seen as legitimate, there is a high probability of the information not being used.

As we continue to complicate our model by simultaneously allowing for multiple sources of information and multiple decision makers and multiple issues, we begin to see how the complexity of the vast majority of sustainable development situations are plagued by interacting problems linked to perceptions of salience, credibility and legitimacy that cross multiple boundaries.

These caricatures illustrate one central challenge to harnessing science and technology for decision making for sustainability - how to maximize the positive functions that boundaries play while minimizing the negative impediments that they often provide in creating salient, credible and legitimate information.

\subsection{Beyond credibility}

Credibility has long been the assumed currency of scientists doing policy-relevant research, with the guiding model being that good, credible science, untainted by politics, can inform the decision making process about the technical aspects of problems and solutions. In the extreme version of such a model, information is produced in the scientific community, walled off from the potentially biasing influence of politics, prepared with the quality-control of peer-review, and then delivered to decision makers in the form of reports. Over the last several decades, critiques and analyses of the role of science and society point to a more nuanced understanding of the relationship between expert knowledge and decision making, one that does acknowledge the importance of credibility while also underscoring other socially mediated attributes that are important in the process of constructing and employing knowledge (Wildavsky 1987; Jasanoff 1990; Lindblom 1990; Funtowicz and Ravetz 1993; Wildavsky 1995; Andrews 2002; Jasanoff, Markle et al. 2002) In addition to scholars of science and society, bench and laboratory scientists from many 
fields struggle with the complexities of producing science that is useful to decision makers without compromising their careers. The letters and fora in scientific journals from fields with socially relevant research such as ecology, nuclear physics, epidemiology and atmospheric chemistry go through cycles of attention to the challenges of producing policyrelevant credible science. Such articles as "How to lose your political virginity while keeping your scientific credibility" (Blockstein 2002) are representative of the challenge felt by scientists themselves.

Drawing on the literatures from the social studies of science, and science, technology, and policy, and bolstered by our empirical work, we have found it useful to begin constructing a framework of knowledge production and use that includes not only credibility, but salience and legitimacy as well. As we will argue below, these three pillars of knowledge production (and their dynamic interactions) seem to be critical determinants of how effective an S\&T system is. We refer to these as attributions because they are not objective, or even readily agreed-upon characteristics of a knowledge production system but rather involve actor-specific judgments using different criteria and standards. Thus salience, credibility, and legitimacy are perceived and judged differently by different audiences (e.g., the U.S. Congress, farmers in Zimbabwe, or fishers in Nova Scotia). Yet attributions also have a public and intersubjective component. Actors are more inclined to judge information as salient, credible, or legitimate when others already judge it as such.

Salience refers to the relevance of information for an actor's decision choices, or for the choices that affect a given stakeholder. One classic pitfall is the identification of interesting and tractable questions within a scientific community that have little relevance outside of it, including no bearing on a decision maker's real-world situation (Toth and Hiznyik 1998). Such questions lack salience for intended users of the information. Farmers need to have information about the timing of rains, not just the predicted amount, as well as information about drought or flood-tolerant plants, how and when to plant them, etc. Information that is timely and informs decision makers about problems that are on their agendas have high salience. Information that arrives at the wrong time in the evolution of an issue (too early, or too late), or that is too broad or narrow in scope, or is not at the right scale for a decision maker, also can fail to influence action for lack of salience (Kingdon 1995). Technologies that are inappropriate for the environmental context in a locale or do not mesh with the existing technological landscape also suffer from lack of salience (Folke, Carpenter et al. 2002). Thus, information about water-efficient technologies and their application in a specific place are highly salient to farmers faced with water shortages. Information about the onset of ENSO-related drought is highly salient to a local water manager or emergency preparedness official. One challenge is to produce information and technologies that meet the needs of decision makers and are thus seen as being salient.

Credibility refers to whether an actor perceives information as meeting standards of scientific plausibility and technical adequacy. Sources of knowledge must be deemed trustworthy and/or believable, along with the facts, theories, and causal explanations invoked by these sources. However, individuals are often unable to independently evaluate the credibility of information. In fact, it is exactly the challenge of translating expert (whether western, indigenous or otherwise) knowledge for the use of nontechnical decision makers that is one of the drivers of the demand for S\&T decision support systems (Tesh and Williams 1996). In this case, credibility is often assessed "by 
proxy", and participants judge credibility by the scientific process (information tends to be discounted by those who believe the process allowed "interests" rather than "science" to determine the results), who participates (key individuals seen as experts imbue credibility), or which organizations are engaged (organizations with a history of getting the "right" answer or valid results accrue credibility). Credibility also interacts with consensus. "Credibility is hard to establish in arenas in which considerable uncertainty and scientific disagreement exists, either about facts or causal relationships. Indeed, actors opposed to an assessment's implications will highlight such uncertainty and disagreement in efforts to question credibility." (Clark, Mitchell et al. in review, p. XX) Finally, credibility has a dynamic component, in which the perception of credibility can evolve as predictive capability can be ascertained over time, as users can ask "did the scientists get it right?"

Legitimacy refers to whether an actor perceives the process in a system as unbiased and meeting standards of political and procedural fairness. Legitimacy involves the belief that S\&T systems are "fair" and consider appropriate values, interests, concerns, and specific circumstances from multiple perspectives. Audiences judge legitimacy based on who participated and who did not, the processes for making those choices, and how information is produced, vetted, and disseminated. When connecting knowledge to action, choices are made about which problems and potential solutions will be considered, and which ones will not. The legitimacy that policy participants and scientific participants attribute to a given process rests on their belief that the processes are respectful of their view and concerns and conform to their perceptions of procedural fairness (Ezrahi 1990; Lindblom 1990; Jäger 1998; Rotmans 1998; Farrell, VanDeveer et al. 2001). In the arena of sustainable development, which is often characterized by "north-south" tensions "[q]uestions of legitimacy regularly arise in assessments that cross the developed-developing country divide. Whether intentionally or as an artifact of unrepresentative participation by developing countries, assessments often fail to include the concerns and perspectives of developing country citizens. Even assessments that are salient and credible to actors in developing countries may not influence those actors if they believe their views and concerns were not considered." (Clark, Mitchell et al. in review, p. XX)

\subsection{Salience, credibility, and legitimacy: thresholds, interactions and balancing tradeoffs}

There are three topics we view as critical with respect to salience, credibility and legitimacy:

\section{Thresholds:}

First, our research supports the notion that efforts to connect knowledge to action are effective only if they are sufficiently salient, credible, AND legitimate with multiple audiences simultaneously. In other words, such efforts are often undermined by perceived deficiencies in a single attribute - thus the danger of only focusing on credibility at the expense of salience or legitimacy. There are numerous examples of information systems, or their outputs, that numerous actors view as having high levels of two of the attributes but fail to influence decision making because of an inadequate level of the third. This is 
represented by the classic case of highly credible and legitimate scientific efforts that are ignored because they are largely seen as irrelevant to the issues that matter most to decision makers. Likewise, even credible and salient information may be disregarded if actors see the process through which it was created as being illegitimate. Threshold levels for the requisite amounts of salience, credibility or legitimacy can vary from issue to issue, and across different functional areas within a system. Moreover, they can also vary over time so that at certain times in the evolution of an issue, salience and legitimacy might be critical to the success of the venture, and at other times the importance of credibility is paramount. This can be seen, for example, in the early efforts of the US National Assessment of Climate Change when regional stakeholder groups were assembled to engage in scoping exercises and agenda-setting in an effort to increase both salience and legitimacy. These early efforts were followed by more selective activities of expert analysis and assessment (an effort to increase credibility.) The point to be made is not where the thresholds are, but simply that they exist and that knowledge production systems that engender perceptions that fall below one of them are likely to be ineffective.

\section{Interactions: tensions and complementarities}

\section{Tensions:}

The attributes of salience, credibility and legitimacy are often dependent of on each other, but unfortunately, as often in negative as in positive ways. Tensions often exist between the three attributes such that efforts to bolster one attribute will often adversely impact another. Engaging decision makers can increase salience by increasing the probability that the right questions will be asked and answered by experts, but it can also decrease the credibility of the information if it appears that science has been biased by the political process. In similar ways, efforts to increase salience can also have negative effects on legitimacy. Including more actors to increase salience may decrease legitimacy by including participants deemed not legitimate to certain other actors. Efforts to increase credibility, by increasing the isolation of science (maintaining strong boundaries) often have the cost of decreasing salience by removing the decision maker from the scoping or agendasetting process. Similar mechanisms that limit participation of decision makers, skeptics, or non-mainstream experts in order to maintain credibility can also decrease the legitimacy of the process. Efforts to increase legitimacy by increasing inclusiveness can have negative effects on salience by re-framing the issue in a way that is irrelevant to a particular audience. Such efforts to increase legitimacy can also decrease credibility as, again, the science can be seen as being "tainted" by politics.

\section{(See Table 1)}

\section{Complementarities}

On the other hand, efforts to increase salience, credibility, or legitimacy can act in a complementary manner, where attempts to increase one also increases another attribute. Efforts to increase salience, for example, by engaging a broader range of decision makers may also increase credibility by better integrating local knowledge into the efforts of outside research or assessment. In similar ways, efforts to increase salience by engaging more stakeholders may also confer greater legitimacy on the process as greater buy-in is established and greater transparency is achieved. Likewise, increasing the participation of a broader group of expertise (e.g., to include developing country scientists in a northern 
dominated assessment) to increase the credibility of the information by including and integrating important knowledge that was formerly missing, also could increase the both the salience (more relevant questions are now asked) and legitimacy by expanding the "ownership" of the process. In parallel, efforts to increase legitimacy may also increase credibility and salience for the same reason described above - as different knowledges are brought into the arena, a more integrated and accurate construction of information may be facilitated while bringing decision makers closer to the research agenda-setting process. (See Table 1)

\section{Balancing Tradeoffs:}

Our third argument follows on the heels of the first two. We find that the most successful efforts to connect knowledge to action are those that are not only effective at engendering favorable perceptions of salience, credibility, and legitimacy, but are also effective at balancing tradeoffs among these three attributes such that none of the three attributes falls below thresholds that will trigger the rejection of information or the resistance to recommended action. We have yet to identify a successful formula for this balancing act, but self-conscious efforts to balance salience, credibility and legitimacy within and across the multiple boundaries of a knowledge production system are more likely to influence action than efforts that ignore these problems.

\subsection{Boundaries and salience, credibility, and legitimacy}

As noted above, multiple boundaries characterize the complex issues of sustainable development. The arenas that intersect in addressing sustainable development consist of multiple dimensions of human activity, dimensions often characterized by significant degrees of segmentation and specialization in order to organize and understand the world. Segmentation and specialization allow for greater cohesion and coherence within differentiated components of a given system, but it does so by creating what one might think of as boundaries between the segments. Such "boundaries", while not rigid or impermeable, delimit such social constructions as functional activities (e.g., knowledge generation, decision making, implementation, etc.), political jurisdictions (e.g., nations), organizational scales (e.g., nations, states, cities, etc.), academic disciplines (e.g., chemistry, physics, economics, anthropology, etc.), as well as different knowledges (e.g., western scientific, traditional, situated, or local). Though serving a range of useful purposes, these boundaries can impede communication, inhibit coordination and hamper integration, especially in interconnected problems that manifest in complex relationships such as those found in human-environment systems.

Perhaps the most fundamental of these boundaries is that between science and decision making in which actors on both sides of the boundary have an interest in maintaining the separation of the two arenas (Gieryn 1995; Guston 1999; Guston 2001): “To shore up their claims on cognitive authority, scientists have to impose their own boundaries between science and policy..." (Jasanoff 1987, p. 199). Scientists have an interest in maintaining a boundary to assure the credibility of their work. Politicians have an interest in maintaining a boundary to ensure their claims of representative legitimacy. But while there is interest in maintaining this boundary, scientists also have an interest in bridging boundaries when they 
seek to have science contribute socially-relevant information that can be used by policy makers and decision-makers.

A similar tension exists for other important boundaries: disciplines exist in order to deepen understanding of issues using specific and agreed upon tools, yet interdisciplinary research is needed to understand and solve problems characterized by complexity and interconnectedness. Boundaries of scale exist in order to balance the efficiencies of centralized governance and the specificity to local context, yet coordination across jurisdictions, from global to local levels, seems to be necessary in addressing transboundary problems, commons problems, and the interactions between global and local change (Wilbanks and Kates 1999; Cash and Moser 2000). Current boundaries exist between different knowledges, a complex result of the evolution of social, economic and cultural dynamics, yet the integration of different ways of knowing is gaining increasing attention (Jasanoff and Martello In review).

Communication and coordination across boundaries can be impeded for the very same reason that they are facilitated within boundaries: the foundations of internal harmony are often the sources of external dissonance. Jargon makes communication efficient within a group, but difficult between groups. When attempting to connect knowledge to action on sustainable development issues, we find that different perceptions and points of emphasis among dissimilar actors and/or across dissimilar realms of action often underpin this dissonance.

This dissonance is often manifest by salience, credibility, and legitimacy being attributed and interpreted differently on different sides of a boundary. This can be illustrated in the case of sustainable development of water resources, where the boundary of interest is scale. The multi-level nature of a problem like aquifer depletion, brings these kinds of differential attributions into sharp focus because issues such as saliency, credibility, and legitimacy can exhibit strong scale-dependence, and attribution of these three qualities can be relatively easily identified and associated with specific levels: what is salient, credible or legitimate to state level actors might be different from and antithetical to what is salient, credible or legitimate to local actors. A state level water plan that might be salient to state actors ("aggregating over the state, this is how water can best be allocated"), might not be salient to local actors ("our concerns are not reflected in the state's overall plan.") Regulations set by a states' department of water resources, while legitimate to state actors ("after all, the state owns the water"), would not be legitimate actions in the eyes of local landowners ("we've hand no input into rules that affect our livelihoods.") Assessment of the aquifer undertaken by a states' geological survey, while credible to state actors ("the state geological survey has the best geologists in the state, plus it's been peer reviewed"), would not be credible in the eyes of local landowners ("they don't understand the specific conditions here.") (Clark, Mitchell et al. in review).

How to understand these dynamics and build organizational structures to avoid the kinds of problems displayed in the illustrations above are the subjects of the next section. In it we outline empirical findings from a number of cases to illustrate the key

\section{EMPIRICAL FINDINGS ON BOUNDARIES AND SALIENCE, CREDIBILITY, AND LEGITIMACY}

Salience, credibility and legitimacy and boundaries

Page 8 of 8 


\subsection{The Research Project}

The work presented in this paper is built on a foundation of cumulative research by members of this research team and other collaborators on the role of science and technology in environmental issues going back more than a decade ${ }^{2}$. This paper describes one focused element of this broad research program: analyzing the institutional dimensions of research, observation, assessment, and decision support systems, and understanding organizational mechanisms which contribute to effective harnessing of S\&T. Toward this end, we have synthesized evidence from three areas. First, we completed a literature review of research that explores the interaction of science and decision making drawing on work from a number of different fields. Second, through ISTS consultative workshops ${ }^{\text {with }}$ practitioners, managers, scientists, and decision makers, we have tapped a wide range of current and past experience, testing our emerging framework against "on the ground" experience and collecting information on multiple issues in multiple contexts. Finally, we have conducted original comparative case research in four topical areas in several regions: water management in the U.S. Great Plains; ENSO forecasting systems in the Pacific region and southern Africa; agricultural research and development within the Consultative Group on International Agricultural Research (CGIAR) system; and fisheries management in the North Atlantic. In the following sections of the paper, we will use these four cases to illuminate our framework.

${ }^{2}$ These include: the Social Learning Project which fashioned a long-term, large-scale overview of how the interplay between ideas and actions across multiple problem areas (stratospheric ozone depletion, acid rain, and climate change) has laid the foundations on which contemporary efforts in global environmental management are now building Social Learning Group, Ed. (2001). Learning to manage global environmental risks: a comparative history of social responses to climate change, ozone depletion and acid rain. Cambridge, MA, MIT Press.; the Global Environmental Assessment (GEA) Project which has provided insights into the role that formal assessment activities play in the international environmental arena Farrell, A., S. D. VanDeveer, et al. (2001). "Environmental assessments: four under-appreciated elements of design." Global Environmental Change 11(4): 311-333, Eckley, N. (2002). "Dependable dynamism: lessons for designing scientific assessment processes in consensus negotiations." Global Environmental Change 12: 15-23, Mitchell, R., W. Clark, et al., Eds. (in review). Global environmental assessments: information, institutions, and influence. Cambridge, MA, MIT Press.; the National Research Council Board on Sustainable Development, which undertook a multi-year assessment seeking "to reinvigorate the strategic connections between scientific research, technologic development, and societies' efforts to achieve environmentally sustainable improvements in human well-being...” National Research Council (1999). Our common journey: a transition to sustainability. Washington, D.C., National Academy Press.; an international multi-institutional effort which explored the role of public participation in the production and use of science for sustainable development Kasemir, B., C. Jaeger, et al., Eds. (2002). Public participation in sustainability science. Cambridge, UK, Cambridge University Press.; the international Initiative on Science and Technology for Sustainability (ISTS), a network of scholars and practitioners seeking to enhance the contribution of knowledge to environmentally sustainable human development which, among other activities, has sponsored a series of regional and topical workshops on science and technology and sustainable development; and the Research and Assessment Systems for Sustainability Program.

${ }^{3}$ These workshops included: "Next Steps in Linking the Global to the Local: Challenges for Research, Assessment and Decision making in a Multi-Level World" at the Open Meeting of the Human Dimensions of Global Change Research Community, Rio de Janeiro, Brazil, October, 2001; Science, Technology and Sustainability: Harnessing Institutional Synergies, Trieste, Italy, organized by the Third World Academy of Sciences (TWAS), February, 2002; Mobilizing Science and Technology for Sustainable Development Cambridge, Massachusetts, United States, April, 2002; Regional Workshops on Science and Technology for Sustainability: Abuja, Nigeria; Chiang Mai, Thailand; Santiago, Chile; Bonn, Germany; Ottawa, Canada (Winter and Spring 2001-2002; Synthesis Workshop on Science and Technology for Sustainable Development, Mexico City, Mexico May, 2002.

Salience, credibility and legitimacy and boundaries

Page 9 of 9 


\subsection{Water Management in the U.S. Great Plains ${ }^{4}$}

Much of the US Great Plains overlies an aquifer that provides the region's water for economic and social life. Producing enormous amounts of wheat, corn, cotton, and livestock, farmers and ranchers of the region depend on water drawn from the High Plains Aquifer. In the last 25 years, however, there have been increasing signs of over- pumping of the resource and resultant economic and social costs (McGuire and Fischer 2000). Complementing a variety of recent studies on the management of the High Plains aquifer (Kromm and White 1991; Kromm and White 1992; Roberts 1992; Emel and Roberts 1995; White and Kromm 1995; Stephenson 1996; Opie 2000), our work has explored how organizational structures have supported or blocked the construction of salient, credible and legitimate information for a range of decision makers about water issues.

Multiple boundaries exist in this arena, the most important being between different levels (e.g., the federal government, state government, multi-county management districts (MMDs), and individual farmers all have a stake in the management of the aquifer), between scientists and decision makers, and between disciplines (agronomy, hydrology, economics, etc.). How are the challenges and opportunities presented by these different cross-boundary perspectives addressed? An example of how hydrologic models of the aquifer are built and used is illustrative of the many oroanizational structures that effectively manage boundaries and produce useful information.

In southwest Nebraska, as in a number of areas in the region, a MMD has been collaborating with the local county extension agent (CEA) to organize the construction of hydrogeologic maps and models to help managers within the district, individual farmers, and state water managers. The process involves actors with a range of different perceptions of what makes information salient, credible and legitimate: farmer advisory groups, hydrogeologists, economists, and agronomists from the University of Nebraska main campus and satellite research stations, hydrogeologists from the US Geologic Survey, state water managers, and technicians and managers from the MMD. The farmer advisory group, MMD and state managers outline the salient questions they want answered and options for regulatory action that can be tested in the model (e.g., What will happen to depletion rates if we put a cap on pumping? What happens if farmers switch from corn to wheat?). The USGS scientists contribute complex modeling capability and knowledge of how the aquifer in S.W. Nebraska relates to the aquifer as a whole, and provides a network of peer-review to assure the credibility of its work. University researchers collaborate on integrating economics, agronomy, and hydrology into the model and coordinate and standardize statewide data on the aquifer, and MMD technicians collect local well-monitoring data.

In what has evolved into a long-term and iterative process that began in the 1970's, both the MMD manager and the CEA act as brokers, mediating the roles of different participants, translating information, and coordinating activities. The process of communication, sharing information, agenda-setting, and utilization of the modeling tools results in attaining threshold levels of salience, credibility, and legitimacy while balancing the trade-offs between them.

${ }^{4}$ Based, in part, on Cash, D. W. (2001). "'In order to aid in diffusing useful and practical information': agricultural extension and boundary organizations." Science, Technology, and Human Values 26(4): 431-453.

${ }^{5}$ Model building is only one of the many activities in which knowledge and action are linked in the manner described. Other activities in the area include the development of efficient irrigation technology, crop management research, creation of incentive structures, and weather monitoring systems. 
With farmers and state managers at the table, questions that are salient to these interests are incorporated in the models. Credibility of the information to all parties is maintained through a system which delimits the role of scientists through negotiation brokered by the MMD and CEA, supports the scientists' use of peer-review, and integrates local-scale data into large-scale models. Through state legislation, regulations set by the MMD, and contracts promulgated by the state university, the manager of the MMD and the CEA are accountable to multiple parties (e.g., voters/state agencies, county advisory committees/the university main campus, respectively). The system of multiple accountability creates legitimacy for the actions of the intermediaries, and contracts clarify the roles and intended outcomes of collaborative efforts. This is also reinforced by a transparent process with multiple gateways in which different actors can enter into the process. Thus, as issues evolve (e.g., water quality rises on the agenda, or feedlots or hog farming become more pervasive and bring a host of new challenges for water management), different actors are engaged, bringing different expertise and interests to the table. The flexibility of the system is such that these new perspectives can be accommodated while reframing what salience, credibility, and legitimacy mean.

As a counterpoint to these kinds of systems, in areas of the region where intermediaries have not played a role in linking multiple nodes in the system, little progress has been made in producing models that can inform the decision making process. Several MMDs in Texas by the late 1990's, for example, realized that there was a need to regulate pumping in some manner. They, however, were not closely connected to university researchers, USGS scientists or state managers. The local managers were poised to regulate, but did not have the credible and salient information that was necessary to convince their constituents that regulation was worthwhile, or what options for regulation were the most effective or feasible. Realizing this predicament, the close of the 1990's saw these MMDs beginning to structure relationships with the appropriate state agencies, universities, and interest groups to begin building the kinds of models that have salience, credibility, and legitimacy in other parts of the region.

\subsection{E1 Niño/Southern Oscillation (ENSO) forecasting in the Pacific and Southern Africa}

Climatic anomalies of 1982/83 and 1992/93 focused worldwide attention on the economic and social impacts of ENSO events. Major efforts were made in the scientific communities in the US and elsewhere to understand the phenomenon and develop tools to predict its onset (O'Brien, Sygna et al. 2000; Glantz 2001). As such tools were developed, different regional systems were established to undertake research, assessment and applications (Glantz, Betsill et al. 1997; Orlove and Tosteson 1999). Two such systems were the focus of our comparative case analysis: The Pacific ENSO Applications Center (PEAC) and the southern African ENSO forecasting system.

PEAC was established in 1994 as a multi-institutional partnership between National Oceanic and Atmospheric Administration (NOAA) agencies, the Universities of Hawaii and Guam, and water, agriculture, and emergency agencies. Its mission is to conduct research and produce information products on climate variability related to the ENSO events in the U.S.-affiliated Pacific Islands (Hawaii, Guam, Samoa, and the Federated States of Micronesia). PEAC acts as a bridge, linking across global through local scales through iterated communication between climate modelers in US agencies, research organizations and universities, on-island data monitors who are part of local management agencies, and 
resource managers. Much like the model building described in SW Nebraska, the system is characterized by iterated two-way communication which encourages the users of ENSO forecasts to articulate needs to modelers and allows modelers to tailor products to the interests and capacities of the users. It also allows the integration of local data (e.g., streamflow information or rainfall data) into larger-scale climatic and weather models. Also like the Great Plains case, PEAC acts an intermediary, brokering communication, translating information and coordinating activities across multiple boundaries. It also is accountable to multiple actors - NOAA through funding contracts and the local managers and agencies who can discontinue engagement with PEAC if the products are not valuable.

PEAC has been able to create salient information through its close engagement of local managers and decision makers. It uses regular meetings, workshops, and other communication to both educate about ENSO, but also try to better understand what are the salient questions to water managers, farmers, emergency management officials and the fishing industry. The engagement of such actors has acted in a complementary way in increasing both credibility and legitimacy. PEAC products are credible in part because they have been created with data inputs from local resource managers. The products are locallyspecific forecasts that contain believable information about events that are familiar to decision makers (e.g., how flow in a specific body of water will change, or how rainfall patterns will deviate from the norm on one side versus another side of an island.) Like in the Great Plains, the process of developing ENSO forecasting tools is viewed as legitimate - all parties that are central to the issue are represented at the table and the process is transparent.

Even though these potential synergies between salience, credibility, and legitimacy are possible in southern Africa, they have not been realized to the same degree. One of the obstacles to use of climate forecasting information is that there is no organization, like PEAC, that is situated to link the multiple nodes of research, assessment, monitoring and decision making. The International Research Institute for Climate Prediction (IRI), funded by NOAA and based at Columbia University in New York in the U.S., has begun to provide some of that role. It is, however, struggling as a foreign entity in southern Africa and needs to link "more actively with local institutions, which can legitimate applications more than IRI may be able to" (Agrawala, Broad et al. 2001, p. 472). Such findings are consistent with other work that has shown that local farmers in southern Africa are not getting forecast information in a timely matter, do not know how to interpret it, and might not have the capacities to make decisions based on it (O'Brien, Sygna et al. 2000).

\subsection{Participatory plant breeding and international through local agricultural research and technology development}

The Consultative Group of International Agricultural Research (CGIAR), and the international agricultural research system in general, has long been the focus of both admiration and critique. CGIAR is seen as coordinating the "green revolution" with both its enormous advances in crop production and questions about its lack of respect for local agroecosystems and increasing dependence of developing country farmers on multi-national seed and fertilizer corporations. Our research focused not on the international system as a whole, but on an emerging effort to link knowledge to action through technology development at one of CGIAR's 16 international research centers, the Centro Internacional de Mejoramiento de Maiz y Trigo, the international maize and wheat improvement center (CIMMYT). As an emerging effort, this case provides evidence of how a large research and 
applications establishment is evolving in structuring its research efforts, partly based on attempts to correct past failures in the system. Future research will be needed to determine the effects of such re-structuring

Agronomists, economists, crop scientists and breeders at CIMMYT have focused on designing crop breeding and testing systems which provide a mix of farmer practices, indigenous knowledge of crops, and modern breeding methods (Bellon 2001). Such efforts, termed Participatory Plant Breeding, are designed to take advantage of both the long-term knowledge that has accrued over many generations and the methods employed by modern plant breeders. Working with farmers, CIMMYT scientists have been testing a variety of different models of integration that can most efficiently and effectively tap into the knowledges of these multiple players in the development of useful technologies.

The effort is an attempt to avoid problems with salience, credibility, and legitimacy that were evident in more conventional "scientific' plant breeding programs. In such programs, scientists were wary of having credibility problems if they engaged farmers and thus could not standardize field trials and experiments. Laboratory and greenhouse research maintained its credibility, but at the cost of salience and legitimacy to farmers. Crops produced in such a process were not tailored to local environments, did not have the qualities desired by farmers (e.g., taste, storage capacity, etc.), and did not fit with existing management regimes. The technology (crops) produced was not salient for the intended user. Likewise, the process was not perceived as being legitimate in the eyes of farmers. Farmers were not consulted or part of the research or development process.

Currently, CGIAR is experimenting with several different models of participatory plant breeding, trying to strike a balance between maintaining the credibility of the scientific research and the salience and legitimacy of the technologies being produced (See Figure 1). As such, CGIAR (CIMMYT in this case) and the National Agricultural Research centers in different countries, are playing the roles of intermediaries, linking organizations and people across boundaries: research and scientists from international institutions; researchers and extension workers in national agricultural research systems; researchers representing multiple disciplines, plant breeders; and farmers.

\subsection{Fisheries assessments and management in the North Atlantic}

Stock assessment science and the establishment of maximum sustainable yields in fisheries management provide another informative glimpse into the dynamics of salience, credibility and legitimacy. In theory, the knowledge to action linkage in this issue area seems straightforward: estimate the population of a given fisheries stock and extrapolate the maximum number of fish that can be harvested in a given year without jeopardizing the stock's ability to sustain itself. When coastal states extended their management jurisdictions through 200 mile exclusive economic zones (EEZs) in the late 1970s and early 1980s, considerable optimism existed in the ability of a new cadre of fisheries scientists armed with sophisticated modeling techniques to anchor a new era of sustainable fisheries policies within EEZs, if not outside of them (Eckert 1972). Two decades later, there is little

\footnotetext{
${ }^{6}$ These finding are based on research conducting in preparation of: Alcock, F. "The Institutional Dimensions of Stock Assessment Processes in the North Atlantic" and "Salience, Credibility and Legitimacy in Connecting Knowledge to Action: the Case of the International Council for the Exploration of the Seas."
} 
evidence to suggest that overfishing has significantly diminished within the vast majority of EEZs (Food and Agricultural Organization of the United Nations (FAO) 2000).

The realm of fisheries management consists of three primary groups, or types of actors: fisheries managers or regulators, fisheries scientists and fishermen. Contestation among these groups arises from different missions, objectives and/or roles within the fishery. All three blame one another for a litany of policy failures. The "functional" boundaries that separate these actors can be considered the most critical in that they demarcate significant differences with respect to the information and knowledge that each of these groups considers salient, credible, and legitimate for the purposes of establishing fisheries policies.

The mutual animosity that exists among these groups can be intense. Scientists often perceive fishermen's observations and associated claims as anecdotal and self-serving, lacking both salience and credibility. Fishermen often perceive scientists and their assessment procedures as aloof and insensitive to the complexity of marine ecosystems, likewise lacking salience and credibility. Dobbs' (Dobbs 2000) book on The Great Gulf that exists between New England's fishermen and its fisheries scientists epitomizes what we conceptualize here as a boundary.

In soliciting advice from scientists in order to regulate fishermen, fishery managers will often be driven by their own goals which must balance the interests of the public and the resource in addition to that of the industry. And fishing industries rarely consist of unified, homogenous actors and measures taken in the interest of conservation usually impact some portions of the industry more severely than others. The rules governing who is given voice in the assessment process and who is not, including the transparency of the process, are inevitably scrutinized in terms of their perceived legitimacy. Those that feel their voices and concerns are marginalized will usually take issue with the resulting scientific advice. Accounts of the stock assessment processes that preceded the collapse of northern cod stocks off the coasts of Newfoundland and Labrador note the acute conflicts between offshore and inshore fishermen. These conflicts were fueled by assessment calculations that factored in catch per unit data from the offshore sector without any parallel mechanism to incorporate observations of declining fish catches among inshore fishermen that disputed offshore claims of a healthy stock. Though the credibility of the resulting assessments were called into question by inshore advocates, a primary criticism can be considered as legitimacy-based in that the inshore viewed the stock assessment process as unfairly considering only offshore observations (Finlayson 1994; Harris 1998).

The institutional relationship between fisheries managers and scientists also shapes perceptions of stock assessment salience, credibility and legitimacy among broader community of stakeholders. As a general rule, the more direct the relationship between fisheries scientists and managers, the more likely the latter will perceive information produced by the former as salient, credible and legitimate. However, unfavorable perceptions of salience, credibility and legitimacy may be correlated with close sciencemanagement ties among the broader community of stakeholders when fishery management organizations are considered politicized. This is increasingly likely when fishery science organizations are embedded within such organizations. In Newfoundland and Nova Scotia, the highly embedded Canadian Atlantic Fishery Scientific Advisory Committee was sharply criticized in the late 1980s and early 1990s by inshore fishermen who viewed it as subject to the politicization they attributed to the Department of Fisheries and Oceans (DFO) itself

\footnotetext{
${ }^{7}$ One could include environmental NGOs as a primary actor in a number of cases as well.
} 
(Finlayson 1994; Harris 1998). The DFO has since responded with institutional reforms that have resulted in a Regional Assessment Process that is much more transparent and open to a broader set of stakeholders (Charles 1997). Preliminary interviews suggest that such reforms have had a positive impact on the legitimacy and the credibility of resulting assessments.

Boundaries between different stakeholders with different roles or functions are not the only important boundary in fisheries. Political boundaries between management jurisdictions, disciplinary boundaries among fisheries scientists, scale boundaries among mismatched to ecosystem parameters, and boundaries between forms of global/scientific vs. local/indigenous knowledge all contribute to dissonant perceptions of salience, credibility and legitimacy that make efforts to connect fisheries knowledge to fisheries action highly problematic. Problems manifest at all levels from global to local, with most boundaries being more or less problematic at different levels of organization.

One fisheries organization that warrants closer attention for its implicit attention to managing the variety of boundaries discussed here is the International Council for the Exploration of the Seas (ICES). Established in 1902, ICES' research agenda, assessment procedures and institutional structure have evolved considerably through its hundred year history with a view toward generating information and advice that is increasingly salient, credible and fegitimate for the nineteen national governments that comprise its stakeholders. ${ }^{\text {S }}$ Such changes have included a democratization of its decision making bodies, a series of initiatives to integrate disparate branches of scientific inquiry and the establishment of dialogue meetings between fisheries managers and fisheries scientists to review research programs as well as the form and basis of scientific advice. Work undertaken by this project is examining its institutional evolution and varying perceptions of salience, credibility and legitimacy that exist within the ICES community.

\section{INSTITUTIONAL IMPLICATIONS: BOUNDARY ORGANIZATIONS, AND SALIENCE, CREDibilitY, AND LEGITIMACY}

Institutions are a pervasive reality which often embody both formal and informal rules and procedures that shape perceptions of salience, credibility, and legitimacy of information produced and transmitted across boundaries (Mitchell 1998; Young 2002; Young 2002). One challenge for institutions is to more effectively bolster salience, credibility, and legitimacy and manage the tradeoffs that become necessary when working across boundaries, as is made evident by the cases described above. We can refer to solving this challenge as the boundary management function, and we can refer to organizations that explicitly focus on this intermediary function as boundary organizations (Guston 1999; Cash 2001; Guston 2001).

Synthesizing the findings from these cases, other examples from our consultative process, and the literature, we suggest several hypothesized organizational structures and strategies that effectively help manage boundaries in linking salient, credible and legitimate science and technology to decision making for sustainable development:

1. Accountability: A critical institutional mechanism which helps assure legitimacy across boundaries is accountability to both sides of the boundary (Guston 1999). When the actors

${ }^{8}$ The nineteen member countries of ICES are: Belgium, Canada, Denmark, Estonia, Finland, France, Germany, Iceland, Ireland, Latvia, the Netherlands, Norway, Poland, Portugal, Russia, Spain, Sweden, the United Kingdom and the United States of America. 
in a boundary organization are dually accountable, they must take into account the interests, concerns and perspectives on both sides of the boundary. In the Great Plains case this is seen for MMD managers who are hired (and fired) by a locally elected board, but also must take actions that are consistent with state regulations enforced by state agencies and the courts. This is also seen for CEAs who are hired by a locally elected board and are accountable to the academic department to which they are affiliated at the state university. Such accountability confers legitimacy on the actions of these players, and is especially useful when they play coordinating roles by linking their organizations to others.

2. Use of Boundary "Objects": In the field of science studies, "boundary objects" has become a useful concept to describe items that "sit between two different social worlds, such as science and nonscience, and they can be used by individuals within each for specific purposes without losing their own identity (Star and Griesemer 1989; Orlove and Tosteson 1999; Guston 2001, p. 400). In the cases we examined, these are hydrologic, fisheries or climate models, forecasts, and assessment reports. They are "objects" over which disparate perspectives can argue and agree, and they can serve as a focal point for common understanding. It is through boundary objects that farmers and economists, state and local officials, emergency managers and climate modelers, economists and chemists, and fishers and marine biologists can come to the table to work upon collaborative tasks. Such collaborative building of a model or forecast or report increases the probability that salient information will be produced by engaging the end-user early in the production of information. They potentially increase credibility by bringing needed (though perhaps disparate) expertise to the table. And they potentially increase legitimacy by providing greater access to the process for multiple perspectives and greater transparency. However, given that they may be "used by individuals within each for specific purposes without losing their own identity", they can also allow different actors to value the boundary objects in different ways - ways that suit their interests, and ways that allow tradeoffs between salience, credibility, and legitimacy to be tempered. A local water manager on Guam can view climate forecasts as a tool to make a quick decision about how to allocate resources, while a scientist can view a forecast as a way of better understanding a complex natural system. Such a dynamic allows both credibility to be maintained (a primary concern of the scientist) at the same time that salience and legitimacy are maintained (primary interests of the end-user.)

3. Participation across the boundary: In systems that effectively link knowledge and action, participation from both sides of a given boundary seems critical (Guston 1999). In the cases we examined, effectiveness is associated with systems that engage multiple actors across multiple boundaries. Cases that did not do this (e.g., the lack of engagement of farmers in southern Africa, modelers from state agencies in Texas, inshore fishers in the North Atlantic, farmers as recipients of "scientific" breeding programs) have special difficulty producing salient information or technology, but also experience difficulties producing legitimate and credible information for critical actors. A boundary organization is one kind of organizational structure that facilitates participation across the boundary. While more research needs to be completed on the role of individuals, preliminary findings suggest that is often individuals who have legitimacy or credibility on both sides of a boundary that are especially useful in making this bridge (e.g., the hydrologist who becomes a manager; the CEA who had experience as a farmer; the farmer who becomes a crop scientist, etc.) 
4. Mediation and a selectively permeable boundary: If what comprises and characterizes boundaries between science and decision making, across levels, and across disciplines is negotiated (Jasanoff 1987), then a critical role in managing boundaries seems to be that of active mediation. As in any negotiation where there are conflicting interests, different perspectives and different ways of understanding, mediation can provide the means by which gains from trade can be made and win-win outcomes can be supported. In our cases, mediation reduces the potential tradeoffs and conflicts between increasing salience, credibility, or legitimacy. As MMD managers and CEAs mediate the collaboration between farmers and modelers they succeed at making the information products salient to users, while at the same time assuring that scientists have control of their research and use peer review to maintain the credibility of their research. Likewise, PEAC's mediation between climatologists and managers in the structuring of forecasts results in the production of information where salience and credibility can be increased complementarily. Managers get timely information about variables that matter to them (when will a drought start), and researchers can build more robust climate models by integrating large-scale with locally collected data. In such a way, the mediator acts to make the boundary selectively porous, allowing bridging the boundary for some purposes (e.g., getting user research needs to researchers), but keeping the boundary solid for others (e.g., keeping the scientific process out of politics).

5. Translation: Some of the most central challenges when crossing boundaries are about differences in jargon, language, and interpretation on opposite sides of a boundary. This challenge is seen in southern Africa ENSO prediction where forecasters are struggling with how to present probabilistic information in a way that is understandable to farmers or managers (O'Brien, Sygna et al. 2000; Patt 2000). Through PEAC's ongoing iterative meetings with modelers and users, users have been able to be educated about how different forecasting information can be presented and interpreted, and users have been able to suggest to modelers what kinds of products are the most useful. In doing so, PEAC plays a central role in translating information between the multiple parties. Likewise, CIMMYT specialists are able to help translate crop breeding information to farmers, and traditional farming information and needs to breeders. Such translation capacities are facilitated by the kinds of people described above - people, who as individuals, bridge boundaries and are comfortable conversing in multiple "languages".

6. Coordination and complementary expertise: Assessing and addressing complex sustainable development issues requires multiple perspectives, disciplines, and interests (Kates 2001; Folke, Carpenter et al. 2002). For assessment activities, coordination is often necessary to take advantage of complementary expertises and conceptual frameworks (e.g., one cannot understand how the change in fisheries will influence local communities without expertise in both marine biology and economics). Likewise, to implement actions, coordination is necessary to avoid multiple entities producing divergent or mutually incompatible policies (state water policy and local water regulations should be mutually supportive.) Our findings suggest that those systems that actively coordinate different entities within the system are better able to take advantage of complementary expertises and produce actions that are more harmonious across different groups (levels, agencies, etc.) In the Great Plains, the vast modeling expertise and resources from a federal agency like USGS can be integrated with local data collection through the coordinating efforts of the CEA. Neither USGS nor the MMD could produce credible and salient models of the aquifer that 
would have locally-specific information if the two expertises were not coordinated. Likewise, traditional farming knowledge and modern scientific breeding techniques are married through the coordination of CIMMYT specialists - an outcome that produces legitimate and salient technologies for farmers, without sacrificing the need for standardization by scientific plant breeders.

\section{Conclusion}

In this paper, we argue that understanding the interactions of these two fundamental characteristics of S\&T systems - boundaries and salience, credibility, and legitimacy - sheds useful light on solving problems of designing effective S\&T systems for sustainable development. At the core of effective systems are the functions of boundary organizations - functions (whether in formal organizations or not) that actively manage the construction, bridging and maintaining of boundaries (boundary-blurring and boundary-drawing as described in Raman \& Guston, this volume). Such functions allow for the reaching of requisite thresholds of salience, credibility, and legitimacy, balancing the tensions and tradeoffs inherent in reaching these thresholds, and taking advantage of complementarities.

The emerging framework presented in this paper supports the general notions of constructivist interpretations of the relationship between science and non-science, but more specifically the ideas of "boundary work" illuminated in this volume. The research described in this paper further contributes to understanding of boundaries and boundary work in two significant ways. First, it extends notions of boundaries to encompass the frontier between arenas other than science and policy. As such, boundaries between disciplines, between organizational levels, and between knowledges generally (science and policy can be seen as a subset of this) figure centrally in understanding the pathways between knowledge and action. In a range of examples, understanding "boundary work" as it is recently evolving (Guston 1999; Guston 2001), is useful in explaining the barriers and bridges in interdisciplinary assessments (e.g., economists and climatologists collaborating on forecasts), multi-scale analysis (e.g., state geologists and local hydrologists collaborating on model building, and assessments which integrate different knowledges (e.g., fisheries modelers working with fisherman in providing stock assessments.

Second, the research presented in this paper helps "illuminate the institutional arrangements, procedures and norms (collectively entitled, 'boundary work') that make for better or worse systems of evidence-based policymaking while simultaneously elaborating on criteria by which such judgments might be made" (Raman \& Guston, this volume, p. XX). As such, we put forth the proposition that, all else being equal, S\&T systems which actively and consciously manage the multiple boundaries within the system, and attend to reaching thresholds of salience, credibility, and legitimacy and balancing tradeoffs between them are more effective than those systems that do not. This is achieved through institutional mechanisms (rules, procedures, norms, etc.) such as establishing dual accountability across the boundary; using "boundary objects"; establishing participation from both sides of a boundary; actively mediating to establish "selectively permeable" boundaries; translating across boundaries; and coordinating complementary expertises. 
TABLE 1: TENSIONS AND COMPLEMENTARITIES AMONG SALIENCE, CREDIBILITY, AND LEGITIMACY

\begin{tabular}{|c|c|c|c|}
\hline $\begin{array}{c}\text { Attempts to } \\
\text { increase... }\end{array}$ & influence salience & influence credibility & influence legitimacy \\
\hline salience & - & $\begin{array}{c}\downarrow \text { by "tainting" } \\
\text { science with politics; } \\
\uparrow \text { by including } \\
\text { "place-based" } \\
\text { knowledge }\end{array}$ & $\begin{array}{c}\uparrow \text { or } \downarrow \text { by increasing } \\
\text { the inclusion of } \\
\text { different decision } \\
\text { makers }\end{array}$ \\
\hline credibility & $\begin{array}{l}\downarrow \text { by isolating the } \\
\text { science and } \\
\text { removing decision } \\
\text { maker input; } \\
\uparrow \text { by including } \\
\text { different scientific } \\
\text { disciplines who ask } \\
\text { different questions }\end{array}$ & 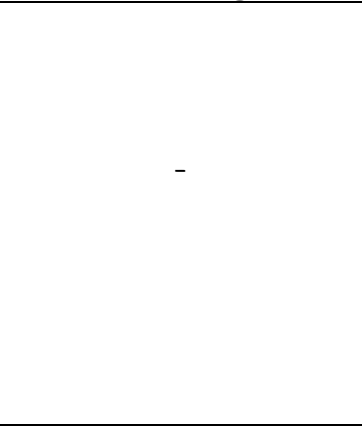 & $\begin{array}{c}\downarrow \text { by limiting } \\
\text { participation and } \\
\text { thus decreasing } \\
\text { process legitimacy; } \\
\uparrow \text { by increasing } \\
\text { inclusiveness of } \\
\text { expertise from } \\
\text { formally excluded } \\
\text { groups }\end{array}$ \\
\hline legitimacy & $\begin{array}{l}\downarrow \text { by changing the } \\
\text { focus of the resulting } \\
\text { information and } \\
\text { therefore its } \\
\text { usefulness to defined } \\
\text { users } \\
\uparrow \text { by increasing } \\
\text { inclusiveness } \\
\therefore \text { increasing } \\
\text { participation of } \\
\text { decision makers }\end{array}$ & $\begin{array}{c}\downarrow \text { by "tainting" } \\
\text { science with politics } \\
\uparrow \text { by increasing the } \\
\text { inclusion of different } \\
\text { knowledges }\end{array}$ & $x_{2}$ \\
\hline
\end{tabular}


Figure 1. Integrating global and local approaches to plant breeding ( $\mathrm{F}=$ farmer; $\mathrm{S}=$ scientist). From (Bellon 2001).

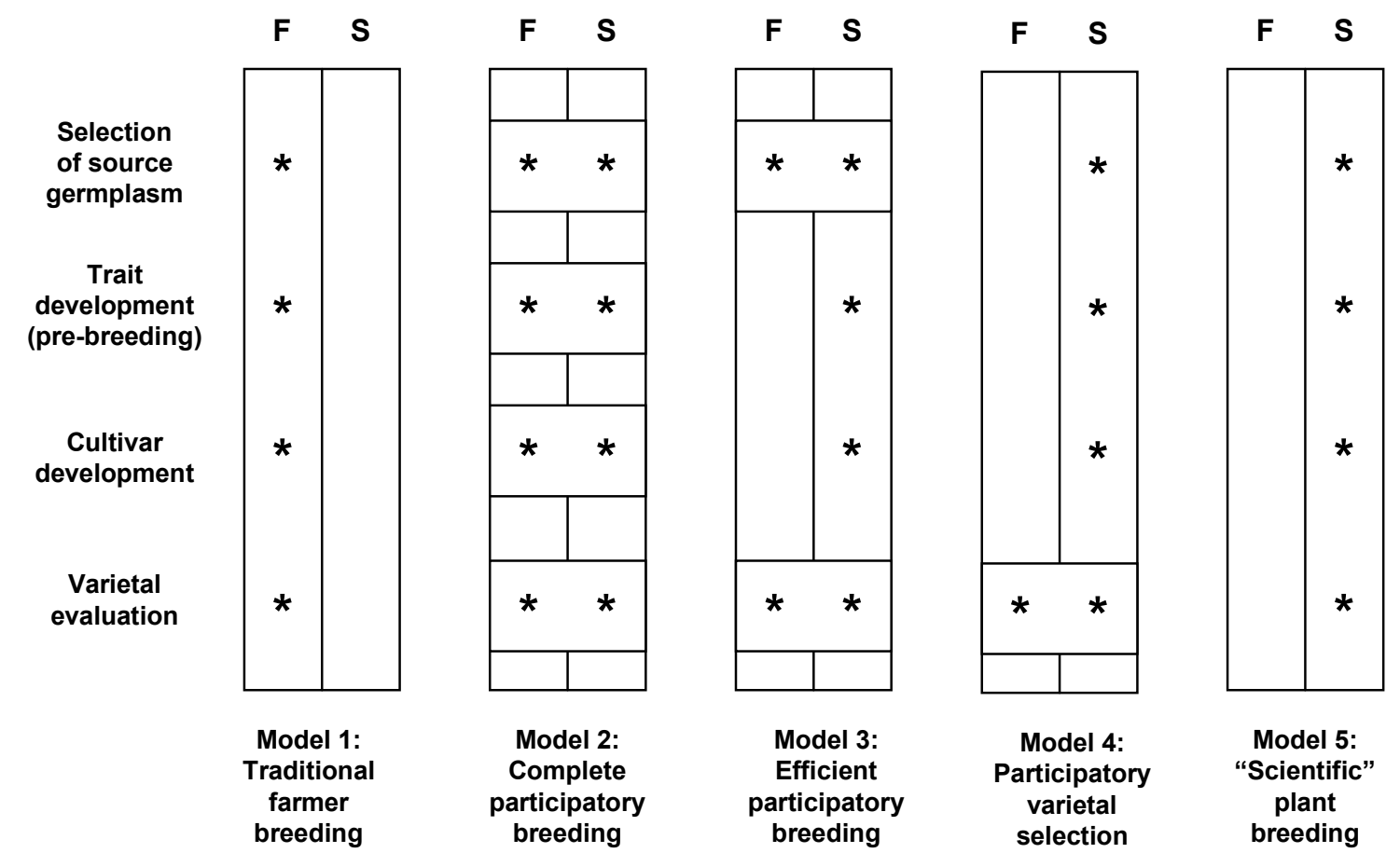




\section{REFERENCES}

Agrawala, S. (1998). "Structural and process history of the intergovernmental panel on climate change." Climatic Change 39(4): 621-642.

Agrawala, S., K. Broad, et al. (2001). "Integrating climate forecasts and societal decision making: challenges to an emergent boundary organization." Science, Technology, and Human Values 26(4): 454-477.

Andrews, C. J. (2002). Humble analysis: the practice of joint fact-finding. Wesport, CT, Praeger.

Bellon, M. R. (2001). Participatory research methods for technology evaluation: a manual for scientists working with farmers. Mexico, D.F., CIMMYT.

Blockstein, D. E. (2002). "How to lose your political virginity while keeping your scientific credibility." Bioscience 52(1): 91-96.

Cash, D. W. (2001). "'In order to aid in diffusing useful and practical information': agricultural extension and boundary organizations." Science, Technology, and Human Values 26(4): 431-453.

Cash, D. W. and S. Moser (2000). "Linking global and local scales: designing dynamic assessment and management processes." Global Environmental Change 10(2): 109-120.

Charles, A. T. (1997). "Fisheries management in Atlantic Canada." Ocean \& Coastal Management 35: 101119.

Clark, W., R. Mitchell, et al. (in review). Information as influence: how institutions mediate the impact of scientific assessments on global environmental affairs. Global environmental assessments: information, institutions, and influence. R. Mitchell, W. Clark, D. W. Cash and F. Alcock. Cambridge, MA, MIT Press.

Dobbs, D. (2000). The great gulf: fishermen, scientists and the struggle to revive the world's greatest fishery. Washington, D.C., Island Press.

Eckert, R. (1972). The enclosure of ocean resources. Palo Alto, CA, Hoover Institute Press.

Eckley, N. (2002). "Dependable dynamism: lessons for designing scientific assessment processes in consensus negotiations." Global Environmental Change 12: 15-23.

Emel, J. and R. Roberts (1995). "Institutional form and its effect on environmental change: the case of groundwater in the southern High Plains." Annals of the Association of American Geographers 85(4): 664-683.

Ezrahi, Y. (1990). The decent of Icarus: science and the transformation of contemporary democracy. Cambridge, MA, Harvard University Press.

Farrell, A., S. D. VanDeveer, et al. (2001). "Environmental assessments: four under-appreciated elements of design." Global Environmental Change 11(4): 311-333.

Finlayson, C. A. (1994). Fishing for truth: a sociological analysis of Northern Cod stock assessments from 1977-1990. St. Johns, ISER/Memorial University.

Folke, C., S. Carpenter, et al. (2002). Resilience and sustainable development: building adaptive capacity in a world of transformations. Paris, France, ICSU. 
Food and Agricultural Organization of the United Nations (FAO) (2000). State of World Fisheries and Agriculture (SOFIA).

Funtowicz, S. O. and J. R. Ravetz (1993). "Science for the post-normal age." Futures 25(7): 739-755.

Gieryn, T. F. (1995). Boundaries of science. Handbook of science and technology studies. S. Jasanoff and e. al. Thousand Oaks, CA, Sage Publications.

Glantz, M., M. Betsill, et al. (1997). Food security in Southern Africa: assessing the use and value of ENSO information. Boulder, CO, Environmental and Societal Impacts Group, National Center for Atmospheric Research.

Glantz, M. H. (2001). Currents of change: El Niño's impact on climate and society. Cambridge, UK, Cambridge University Press.

Guston, D. H. (1999). "Stabilizing the boundary between politics and science: the role of the Office of Technology Transfer as a boundary organization." Social Studies of Science 29(1): 87-112.

Guston, D. H. (2001). "Boundary organizations in environmental policy and science: an introduction." Science, Technology, and Human Values 26(4): 399-408.

Harris, M. (1998). Lament for an ocean: the collapse of the Atlantic cod fishery. Toronto, McClelland \& Stewart.

Jäger, J. (1998). "Current thinking on using scientific findings in environmental policy making." Environmental Modeling and Assessment 3: 143-153.

Jasanoff, S. (1990). The fifth branch: science advisors as policymakers. Cambridge, MA, Harvard University Press.

Jasanoff, S., G. E. Markle, et al., Eds. (2002). Handbook of science and technology studies. Thousand Oaks, CA, Sage Publications.

Jasanoff, S. and M. L. Martello, Eds. (In review). The patchwork planet: local and global in environmental politics, MIT Press.

Jasanoff, S. S. (1987). "Contested boundaries in policy-relevant science." Social Studies of Science 17: 195-230.

Kasemir, B., C. Jaeger, et al., Eds. (2002). Public participation in sustainability science. Cambridge, UK, Cambridge University Press.

Kates, R. W., William C. Clark, Robert Corell, J. Michael Hall, Carlo C. Jaeger, Ian Lowe, James J. McCarthy, Hans Joachim Schellnhuber, Bert Bolin, Nancy M. Dickson, Sylvie Faucheux, Gilberto C. Gallopin, Arnulf Gruebler, Brian Huntley, Jill Jäger, Narpat S. Jodha, Roger E. Kasperson, Akin Mabogunje, Pamela Matson, Harold Mooney, Berrien Moore III, Timothy O'Riordan, Uno Svedin (2001). "Sustainability science." Science 292: 641-642.

Kingdon, J. W. (1995). Agendas, alternatives, and public policies. New York, HarperCollins.

Kromm, D. E. and S. E. White (1991). "Reliance on sources of information for water-saving practices by irrigators in the high plains of the U.S." Journal of Rural Studies 7(4): 411-421.

Kromm, D. E. and S. E. White, Eds. (1992). Groundwater exploitation in the High Plains. Lawrence, KS, University Press of Kansas.

Salience, credibility and legitimacy and boundaries

Page 22 of 22 
Lindblom, C. E. (1990). Inquiry and change: the troubled attempt to understand and shape society. New Haven, CT, Yale University Press.

McGuire, V. L. and B. C. Fischer (2000). Water-level changes in the High Plains Aquifer - 1980 to 1998 and 1997 to 1998. Denver, CO, U.S. Geological Survey,.

Mitchell, R., W. Clark, et al., Eds. (in review). Global environmental assessments: information, institutions, and influence. Cambridge, MA, MIT Press.

Mitchell, R. B. (1998). "Sources of transparency: information systems in international regimes." International Studies Quarterly 42: 109-130.

National Research Council (1999). Our common journey: a transition to sustainability. Washington, D.C., National Academy Press.

O'Brien, K., L. Sygna, et al. (2000). Is information enough? User responses to seasonal climatre forecasts in southern Africa. Oslo, Norway, Center for International Climate and Environmental Research.

Opie, J. (2000). Ogallala: water for adry land. Lincoln, NE, University of Nebraska Press.

Orlove, B. S. and J. L. Tosteson (1999). The application of seasonal to interannual climate forecasts based on El Niño-Southern Oscillation (ENSO) events: Lessons from Australia, Brazil, Ethiopia, Peru, and Zimbabwe. draft. Berkeley, CA, Institute of International Studies, University of California.

Patt, A. (2000). Communicating probabilistic forecasts to decision makers: a case study of Zimbabwe. Cambridge, MA, Kennedy School of Government, Harvard University.

Price, D. K. (1965). The scientific estate. Cambridge, MA, Belknap Press.

Raustiala, K. and D. Victor (1996). "Biodiversity since Rio: The future of the Convention on Biological Diversity." Environment 38(4): 17-20, 37-45.

Roberts, R. S. (1992). Groundwater management institutions. Groundwater exploitation in the High Plains. D. E. Kromm and S. E. White. Lawrence, KS, University Press of Kansas: 88-107.

Rotmans, J. (1998). "Methods for IA: the challenges and opportunities ahead." Environmental Modeling and Assessment 3: 155-179.

Social Learning Group, Ed. (2001). Learning to manage global environmental risks: a comparative history of social responses to climate change, ozone depletion and acid rain. Cambridge, MA, MIT Press.

Star, S. L. and J. R. Griesemer (1989). "Institutional ecology, 'translations' and boundary objects: amateurs and professionals in Berkeley's Museum of Vertebrate Zoology, 1907-39." Social Studies of Science 19(3): 387-420.

Stephenson, K. (1996). "Groundwater management in Nebraska: governing the commons through local resource districts." Natural Resources Journal 36: 521-538.

Tesh, S. N. and B. A. Williams (1996). "Identity politics, disinterested politics, and environmental justice." Polity 18: 285-305.

Toth, F. L. and E. Hiznyik (1998). "Integrated environmental assessment methods: evolution and application." Envionmental Modeling and Assessment 3: 193-207. 
White, S. E. and D. E. Kromm (1995). "Who should manage the High Plains aquifer? The irrigators' perspective." Water Resources Bulletin 31(4): 715-727.

Wilbanks, T. J. and R. W. Kates (1999). "Global change in local places: how scale matters." Climatic Change 43(3): 601-628.

Wildavsky, A. (1995). But is it true? A citizen's guide to environmental health and safety issues. Cambridge, MA, Harvard University Press.

Wildavsky, A. B. (1987). Speaking truth to power: the art and craft of policy analysis. New Brunswick, NJ, Transaction Books.

Young, O. R. (2002). "Evaluating the success of international environmental regimes: where are we now?" Global Environmental Change 12: 73-77.

Young, O. R. (2002). Institutional interplay: the environmental consequences of cross-scale interactions. The drama of the commons. E. Ostrom, T. Dietz, N. Dolsaket al. Washington, D.C., National Academy Press: 259-291. 